\title{
Least damaging invasive ventilation during extracorporeal respiratory support after lung transplantation
}

\author{
Vasileios Zochios $^{1,2}$, Aristotle D. Protopapas ${ }^{3}$ \\ ${ }^{1}$ Department of Critical Care Medicine, University Hospitals Birmingham National Health Service Foundation Trust, Queen Elizabeth Hospital \\ Birmingham, Birmingham, UK; ${ }^{2}$ Birmingham Acute Care Research Group, Institute of Inflammation and Ageing, Centre of Translational \\ Inflammation Research, University of Birmingham, Birmingham, UK; ${ }^{3}$ Department of Surgery and Cancer, Imperial College London, London, UK \\ Correspondence to: Vasileios Zochios. Department of Critical Care Medicine, University Hospitals Birmingham National Health Service \\ Foundation Trust, Queen Elizabeth Hospital, Edgbaston, Mindelsohn Way, Birmingham, B15 2GW, UK; Birmingham Acute Care Research \\ Group, Institute of Inflammation and Ageing, Centre of Translational Inflammation Research, University of Birmingham, Birmingham, UK. \\ Email: vasileioszochios@doctors.org.uk.
}

Submitted Apr 06, 2019. Accepted for publication May 19, 2019.

doi: 10.21037/acs.2019.05.16

View this article at: http://dx.doi.org/10.21037/acs.2019.05.16

We were interested to read of the surgical experience at Turin over the last decade with 25 veno-venous (VV) extracorporeal membrane oxygenation (ECMO) runs in support of cadaveric sequential lung transplantation (1). This is a great piece of work indeed in an expanding application of artificial organs.

There are certain points of interest to be discussed from the cardiothoracic intensivist's and perioperative physician's corner:

(I) 'Graft protective' invasive ventilation: Boffini et al. did not include perioperative or VVECMO ventilatory strategy variables such as tidal volume, plateau pressure $\left(\mathrm{P}_{\text {plat }}\right)$, positive-end expiratory pressure (PEEP) or driving pressure $\left(\triangle \mathrm{P}=\mathrm{P}_{\text {plat }}\right.$ - total PEEP) in the univariate or multivariate analyses of risk factors for postoperative need for VVECMO, liberation from ECMO or in-hospital mortality (1). Any positive pressure ventilation could in theory lead to ventilator-induced lung injury (VILI) and it has been shown that healthy ('non-injured') lungs are at risk of subclinical VILI (2). There is lack of rigorous prospective data relating to the optimal invasive ventilatory strategy for the deceased organ donor and lung transplant recipient. One might argue that even if a 'low tidal volume' ventilation was utilized in the study cohort, primary graft dysfunction due to VILI is still a possibility. It stands to reason that during
VVECMO support in the context of primary graft dysfunction ('injured lungs') a 'least damaging' or 'ultra-protective' ventilatory strategy is adopted. 'Ultra-low' tidal volumes $(3-4 \mathrm{~mL} / \mathrm{kg}$ predicted body weight) to limit total lung and dynamic strain as reflected by $\mathrm{P}_{\text {plat }}\left(\mathrm{P}_{\text {plat }}<25 \mathrm{cmH}_{2} \mathrm{O}\right)$, combined with low respiratory rate $(5-10$ breaths per minute), and low fraction of inspired oxygen $\left(\mathrm{FiO}_{2}<0.4\right)$ seems a reasonable 'graft-protective' strategy that could potentially improve outcomes in lung transplant patients on VVECMO support (3). Driving pressure in patients with severe acute respiratory distress syndrome (ARDS) requiring VVECMO has been shown to be independently associated with in-hospital mortality $(3,4)$. The aforementioned parameters of pulmonary mechanics during VVECMO for primary graft dysfunction, their role in mitigating VILI and the concept of elimination of invasive ventilation during VVECMO support should be tested in large scale prospective trials.

(II) Right ventricle (RV)-protective ventilation: VV ECMO reverses hypoxemia and hypercapnia and also facilitates low volume/low pressure mechanical ventilation leading to unloading of the RV which may be impaired in acute severe respiratory failure due to increased RV afterload (5). Perioperative RV injury in the setting of primary 
graft dysfunction could potentially worsen outcomes and echocardiography-guided ventilatory management during VVECMO support may confer hemodynamic benefit.

Minimizing VILI and RV injury in the high risk lung transplant patient population using least injurious ventilation settings (low tidal volume, low $\mathrm{P}_{\text {plat }}$, low $\Delta \mathrm{P}$ ) is paramount. The causative link, if any, between VILI, $\mathrm{RV}$ dysfunction and primary graft dysfunction in lung transplantation and the protective role of perioperative extracorporeal respiratory support is yet to be determined.

The effect of extracorporeal technologies and noninjurious ventilation strategies on patient-centred outcomes in recipients with primary graft dysfunction needs to be tested in large randomized controlled trials.

\section{Acknowledgments}

Funding: Dr. Zochios is supported by an Academic Clinical Fellowship from the National Institute for Health Research (ACF-2016-09-011).

\section{Footnote}

Conflicts of Interest: The authors have no conflicts of interest to declare.

Cite this article as: Zochios V, Protopapas AD. Least damaging invasive ventilation during extracorporeal respiratory support after lung transplantation. Ann Cardiothorac Surg 2019;8(4):516-517. doi: 10.21037/acs.2019.05.16

\section{References}

1. Boffini M, Simonato E, Ricci D, et al. Extracorporeal membrane oxygenation after lung transplantation: risk factors and outcomes analysis. Ann Cardiothorac Surg 2019;8:54-61.

2. Güldner A, Kiss T, Serpa Neto A, et al. Intraoperative protective mechanical ventilation for prevention of postoperative pulmonary complications: a comprehensive review of the role of tidal volume, positive end-expiratory pressure, and lung recruitment maneuvers. Anesthesiology 2015;123:692-713.

3. Patroniti N, Bonatti G, Senussi T, Mechanical ventilation and respiratory monitoring during extracorporeal membrane oxygenation for respiratory support. Ann Transl Med 2018;6:386.

4. Serpa Neto A, Schmidt M, Azevedo LC, et al. Associations between ventilator settings during extracorporeal membrane oxygenation for refractory hypoxemia and outcome in patients with acute respiratory distress syndrome: a pooled individual patient data analysis : Mechanical ventilation during ECMO. Intensive Care Med 2016;42:1672-84.

5. Reis Miranda D, van Thiel R, Brodie D, Right ventricular unloading after initiation of venovenous extracorporeal membrane oxygenation. Am J Respir Crit Care Med 2015;191:346-8. 